Revista de Economia Política, vol. 41, $n^{\circ}$ 2, pp. 426-443, abril-junho/2021

\title{
Sindicalismo, reestruturação produtiva e capitalismo financeiro no Brasil
}

\author{
Unionism, productive restructuring and finance capitalism
}

\author{
JANAÍNA DE OLIVEIRA* \\ MARIA CHAVES JARDIM** \\ SIDNEY JARD DA SILVA***
}

RESUMO: O artigo se situa no âmbito das discussões contemporâneas que desafiam a sociologia econômica e a sociologia do trabalho a refletir sobre um novo fenômeno socioeconômico: a chegada de sindicalistas no mercado financeiro, via criação e, sobretudo, a gestão de fundos de pensão. Atores sociais da construção deste novo fenômeno financeiro, os sindicalistas passam a (re)significar não somente suas estratégias, mas também seus discursos, agregando questões morais e sociais aos interesses do mercado. $\mathrm{O}$ trabalho demonstra que o novo éthos do sindicalismo brasileiro busca utilizar a própria lógica do capital na resistência contra a financeirização da economia e a reestruturação produtiva.

PALAVRAS-CHAVE: Capitalismo financeiro; fundos de pensão; sindicato; reestruturação produtiva.

ABSTRACT: The article is part of contemporary discussions that challenge economic sociology and the sociology of work to reflect on a new socioeconomic phenomenon: the arrival of trade unionists in the financial market, through creation and, above all, the management of pension funds. Social actors of the construction of this new financial phenomenon, unionists come to (re)signify not only their strategies, but also their speeches, adding moral and social questions to the interests of the market. The work demonstrates that using the logic of capitalism itself in the fight against financialization of the economy and the productive restructuring would be the new ethos of Brazilian unionism.

KEYWORDS: Finance capitalism; pension funds; trade unions; productive restructuring. JEL Classification: J51.

* Doutoranda do Programa de Pós-Graduação em Ciências Sociais - UNESP. Araraquara/SP, Brasil. E-mail: janalive@gmail.com. Orcid: https://orcid.org/0000-0002-3244-6109.

* Professora do Departamento de Ciências Sociais da Faculdade de Ciências e Letras da UNESP de Araraquara, Araraquara/SP, Brasil. E-mail: maria.jardim@unesp.br. Orcid: https://orcid.org/0000-00015715-1430.

*** Professor do Centro de Engenharia, Modelagem e Ciências Sociais Aplicadas da Universidade Federal do ABC - CECS/UFABC, Santo André/SP, Brasil. E-mail: sidney.jard@ufabc.edu.br. Orcid: https:// orcid.org/0000-0003-3444-1763. Submetido: 5/Fevereiro/2019; Aprovado; 20/Agosto/2020. 


\section{INTRODUÇÃO}

O artigo se situa no âmbito de discussões contemporâneas que desafiam a sociologia econômica e a sociologia do trabalho a refletir sobre um novo fenômeno socioeconômico: a chegada de sindicalistas no mercado financeiro, o que por sua vez desarticula as centralidades e as fronteiras tradicionais entre sindicatos/ sindicalistas, de um lado, e finanças/financistas, de outro. $\mathrm{O}$ fenômeno permite tanto uma nova interpretação da crise sindical, já que as estratégias mais tradicionais, como as greves, estariam em arrefecimento, quanto a intepretação da ressignificação das lutas sindicais, já que determinados segmentos sindicais estariam investindo na criação e gestão de fundos de pensão, um tipo de previdência complementar que movimenta o equivalente a $20 \%$ do PIB brasileiro (Jardim; Jard da Silva, 2015; Sória e Silva, 2015).

Nesta perspectiva, o acesso de sindicalistas e determinados sindicatos ao mercado financeiro, via criação e, sobretudo, a gestão de fundos de pensão, alteraria consideravelmente as relações sindicato-mercado, desenhando um novo fenômeno sociológico.

Atores sociais da construção deste novo fenômeno financeiro, os sindicalistas passam a (re)significar não somente suas estratégias, mas também seus discursos, agregando questões morais e sociais aos interesses do mercado. Ademais, o discurso de deslegitimação da previdência pública, assim como as tensões entre sindicalistas que defendem a previdência privada e sindicalistas que se opõe à mesma emergem no mundo do trabalho.

É sobre esse conjunto de arrazoado que promove tanto a quebra de fronteira disciplinar - já que para além do interesse sociológico, o tema também é objeto da economia, do direito e da política pública - quanto a ressignificação empírica do conceito de sindicato e de mercado que esse artigo se debruça.

O texto está dividido em quatro partes. A primeira é destinada a entender as mudanças econômicas e sociais que o Brasil vivenciou nos anos de 1980 com o processo de redemocratização política, o reconhecimento legal dos sindicatos e o fortalecimento institucional das entidades sindicais (Almeida, 1996). Em seguida, tratamos da década de 1990 que, para alguns estudiosos, anuncia a mudança do modelo de produção industrial, a reestruturação produtiva, a proeminência do capitalismo de finanças e a crise do sindicalismo. ${ }^{1} \mathrm{Na}$ terceira parte, apresentamos as estratégias sindicais que se orientam pelo mercado financeiro. Nas Considerações Finais, realizamos uma reflexão sobre os achados substantivos do trabalho, especialmente sobre a participação sindical na gestão dos fundos de pensão.

\footnotetext{
${ }^{1} \mathrm{O}$ capitalismo de finanças representa as transformações não apenas enquanto uma redistribuição de recursos financeiros e de rendas entre os diversos atores econômicos, mas uma modificação profunda nas relações e nas regras sociais que regem essas relações, apontando uma evidente natureza social das finanças (Jardim, 2011).
} 


\section{SINDICATO E REESTRUTURAÇÃO PRODUTIVA}

Durante os anos 1968-1978, momento mais repressor da ditadura militar (1964-1985), o sindicalismo brasileiro foi predominantemente um sindicalismo de governo, ou seja, atrelado ao Estado (Boito Jr., 1991). Neste período, os sindicatos oficiais tinham em suas direções os chamados "dirigentes pelegos". As poucas lideranças que ousavam confrontar a política governamental eram depostas e as entidades sindicais sofriam intervenção estatal (Weffort, 1972).

No fim da ditadura militar e início da redemocratização houve um "afrouxamento" do controle do Estado sobre os sindicatos. O desfecho deste processo foi a crescente emergência de novas lideranças sindicais que passaram a organizar e dirigir os trabalhadores. Estas mudanças estão circunscritas em relevantes marcos históricos como o ressurgimento das greves entre os anos de 1978 e 1980; a criação da Central Única dos Trabalhadores (CUT), em 1983; e a política liberalizante iniciada pelo ministro do Trabalho Almir Pazzianotto, em 1985, a qual suspendeu o controle direto das Delegacias Regionais do Trabalho (DRTs) sobre as entidades sindicais (Boito Jr., 1991).

Assim, na década de 1980 o movimento sindical brasileiro viveu um momento particularmente positivo, inclusive com a criação e o fortalecimento de centrais sindicais que passariam a coordenar nacionalmente as ações dos trabalhadores (Antunes, 1995). Outros fatores que favoreceram a ação sindical neste período foram: de um lado, a transição política para a democracia e, de outro, a crise econômica inflacionária, sobre as quais o movimento sindical se apoiou para organizar as grandes greves dos anos de 1970-1980 (Santana, 2000).

Segundo Noronha (1991), as greves brasileiras dos anos 1970 e 1980 representavam demandas trabalhistas reprimidas durante os anos de autoritarismo, descontentamento social e consolidação de novas lideranças sindicais. Estas estavam inicialmente concentradas no setor industrial, na área metalúrgica da região do ABC Paulista; mas logo se espalharam para outros municípios, estados e categorias profissionais do setor privado e público. Para este autor, as greves foram a expressão mais evidente dos interesses não pactuados e altamente competitivos e conflituosos do processo de transição do Brasil.

No final dos anos 1980, o país ainda apresentava altas taxas de greve, devido aos conflitos trabalhistas na esfera pública. O avanço do sindicalismo do setor público, por sua vez, foi resultante da democratização do Estado e da expansão dos serviços públicos. Esse novo sindicalismo gerou novos líderes sindicais, com reivindicações específicas, que deram nova roupagem ao movimento sindical brasileiro (Jard da Silva, 2001; 2013).

Com a abertura econômica dos anos 1990, a reestruturação produtiva e a política de privatizações, os sindicatos se viram novamente diante de uma complexa situação, que incluía o aumento do desemprego e a precarização das relações de trabalho. Neste contexto, destacam-se os efeitos ocorridos no mundo do trabalho, tais como a queda na taxa de sindicalização e o arrefecimento de práticas tradicionais de ação sindical (Jácome Rodrigues, 2002; Ramalho e Santana 2003). 
Acentuaram-se as formas de contratações flexíveis, tais como tempo parcial, trabalho precário e/ou subempregos, ao mesmo tempo em que as políticas de proteção do indivíduo dentro e fora do mercado de trabalho foram sendo substituídas por políticas de aumento da competitividade (Boito Jr., 2002).

Assim, o trabalho, um dos eixos centrais de vertebração da ordem social moderna, ficou enfraquecido com a dita "crise do mundo do trabalho". Para Ramalho e Santana (2003), essa é a nova era das desigualdades, marcada pela perda de institutos de proteção social, aumento das taxas de pobreza global e disparidades sociais e ampliação da vulnerabilidade social e econômica.

Diante deste quadro, para diversos pesquisadores os sindicatos enfrentam uma significativa "crise", em que suas políticas e estratégias de ação parecem impotentes para deter a destruição dos direitos trabalhistas. Em outras palavras, os sindicatos encontram dificuldades de se relacionar com uma força de trabalho de características diversas, instáveis e heterogêneas (Rodrigues, 2002).

Para Jácome Rodrigues (1991) a estratégia sindical nos anos 1990 passou a ser essencialmente defensiva, atuando pela garantia do emprego, a participação nos resultados e na mudança da gestão e organização do trabalho. Isso ocorreu devido à reestruturação do processo produtivo, levando à precarização nas relações de produção e uma nova relação entre capital e trabalho. Portanto, se nos anos 1980 a preocupação do movimento sindical era com questões econômicas e salariais, nos anos 1990 esta preocupação foi substituída pela garantia de emprego e pelo combate ao desemprego (Santana, 2000).

Ainda segundo Jácome Rodrigues (1991), houve mudança no sindicalismo cutista, principalmente nos sindicatos do $\mathrm{ABC}$, que estaria buscando um comportamento do tipo "cooperação conflitiva”, ou seja, embora o conflito seja explícito, há crescente preocupação com a cooperação. A necessidade de conceber e negociar novas bases de solidariedade representaria um dos grandes desafios para as entidades sindicais. Ramalho e Santana (2003), por sua vez, falam do surgimento de um "sindicalismo de conciliação".

Diante deste novo contexto econômico, político e social de transformação do mundo do trabalho, discutiremos as novas modalidades de ações sindicais no Brasil na próxima seção deste artigo.

\section{RESSIGNIFICAÇÃO DAS LUTAS SINDICAIS}

No debate sobre a crise sindical, Beynon (2003, p. 58) afirma que: "É bastante comum referir-se ao declínio da influência dos sindicatos na política nacional, ao declínio do número de filiados e à dificuldade que eles têm, como organizações nacionais, de lidar com sistemas globais de produção e distribuição, como crise". No entanto, o mesmo autor acrescenta que há certo exagero em torno da questão da crise do sindicalismo, uma vez que, embora tenha reduzido o número de filiados às entidades sindicais em vários países, há também fortes evidências internacionais 
de que os trabalhadores continuam à se contrapor a pressão que sofrem dos empresários e governos.

Rodrigues (2002), por sua vez, afirma que a dificuldade para a mobilização dos trabalhadores e para os sindicatos conservarem seu tradicional papel de representação de interesses advém do fato de que nem todas as mudanças foram desfavoráveis aos empregados, embora possam ter sido negativas para o sindicalismo e para o poder sindical. Nessa perspectiva, houve alterações no poder de barganha dos sindicatos e expansão das novas formas de organização, que premiam a flexibilidade e a participação do empregado e a diversificação das preferências dos trabalhadores.

No final dos anos 1990, voltam ao cenário temas que não se relacionavam somente à melhoria das condições de trabalho e às lutas operárias, mas também à instrumentos de eficiência produtiva, dado o ambiente fabril que demandava flexibilidade dos sistemas de produção. Segundo Salerno (2004), a ligação entre organização do processo de trabalho e condições sociopolíticas não tem sido suficientemente analisada pelos estudiosos do sindicalismo.

O mesmo autor afirma que não foram todas as empresas que sofreram com a competição internacional, ou seja, os ambientes não são sempre uniformes, pois o espaço dos negócios é distinto para cada companhia. Isso obscurece outros condicionantes, principalmente os sociopolíticos relativos às relações de trabalho tomadas em sentido amplo e não somente através das relações sindicais formais. A citação abaixo indica exemplos desse modelo de estudos que se instaurou:

O refluxo do movimento operário e o consequente aumento de poder das empresas em sua relação com os trabalhadores manifesta-se na produção crítica sobre processo de trabalho e sobre o trabalho de maneira geral, de forma bastante intensa. Relações de trabalho "sai de moda". Da discussão de organização do processo de trabalho e qualificação desqualificação-requalificação, passa-se à de "formação profissional”, não sem esquecer que recursos do Fundo de Amparo ao Trabalhador (FAT) foram usados para financiar vários estudos acadêmicos e programas sindicais. Há também a perspectiva do estudo do trabalho. (Salerno, 2004, p. 28)

Ramalho e Santana (2003, p. 36) concordam que os sindicatos têm se defrontado com questões complexas, mas apostam no sucesso das suas estratégias em resposta à "crise". No entanto, o debate produzido pela percepção desta "crise" revela divergência quanto ao modo de interpretar os efeitos das mudanças sobre a instituição sindical. Para Rodrigues (2002) esse processo aponta para um declínio inexorável do sindicato, enquanto outros estudiosos consideram que a crise não é da instituição de representação dos trabalhadores, mas de um tipo de organização sindical específica atingida duramente pelas transformações no mundo do trabalho.

Ramalho e Santana (2002), por exemplo, apontam diversos fatores que exprimem a razão para justificar esse momento de "crise". Os principais estão associados às mudanças na estrutura produtiva em função da flexibilização das relações 
de trabalho e o crescimento do trabalho em tempo parcial, tempo determinado e por conta própria; do uso intensificado da subcontratação, do trabalho em domicílio e do aumento da participação feminina no mercado de trabalho, além do crescimento do desemprego; e da redução do emprego industrial provocada pelo avanço da automação.

O aumento das terceirizações, aliado aos fatores citados acima, intensificou ainda mais o processo de precarização do trabalho. O que está ocorrendo é uma verdadeira exportação de tensões, conflitos e da própria legislação trabalhista para fora das unidades produtivas, já que mesmo alocados dentro de seu espaço os terceirizados são trabalhadores de outro patrão e de outro padrão de relações de trabalho. Outro exemplo ainda mais emblemático é quando as grandes empresas transformam as casas de seus funcionários em minifábricas, em uma reapropriação do trabalho doméstico, retrocedendo a legislação trabalhista e a representatividade sindical.

Robert Castel (2005), a partir de uma perspectiva de contestação e complexificação das análises relativas ao modelo flexível, propõe associar a discussão sobre trabalho e relações salariais à questão social, ao colocá-la não na retaguarda, mas no centro da análise sobre precariedade, pobreza e exclusão. O trabalho é pensado pelo autor não como relação técnica de produção, mas como um suporte privilegiado de inscrição na estrutura social. Além disso, reconhece uma forte correlação entre o lugar ocupado na divisão social do trabalho e a participação nas redes de sociabilidade e nos sistemas de proteção que amparam o indivíduo diante dos acasos da existência, possibilitando zonas de coesão social.

Nessa perspectiva, associar-se trabalho estável e inserção relacional sólida vai caracterizar uma área de integração, enquanto a ausência de participação em qualquer atividade produtiva e o isolamento relacional vão ter como consequência os efeitos negativos da exclusão. Castel (2005) afirma ainda que a problemática da coesão social não é a do mercado, pois a solidariedade não se constrói em termos de competitividade e de rentabilidade.

Ainda sobre a discussão da crise sindical, Ramalho e Santana (2002) demonstram o crescimento do conflito de interesses e da competição entre os trabalhadores, isto é, uma ruptura que separa os trabalhadores masculinos, qualificados e de meia-idade - que tradicionalmente dominam a política dos sindicatos e da representação de interesses na empresa - e os grupos mais sujeitos aos riscos do mercado de trabalho - negros, mulheres, jovens, idosos, deficientes, entre outros. Com o desemprego estrutural, quase todas as reivindicações e negociações sindicais tendem a favorecer o primeiro grupo - mais hegemônico - em detrimento dos demais. A crise, quando analisada pela ótica na sociologia do trabalho clássica, não só aumenta o poder do capital, mas também repercute na classe trabalhadora, instaurando o que seria um corte entre vencedores e perdedores.

Neste contexto, o sindicalismo está imerso em muitos problemas, mas o principal é o desemprego em massa que se tornou um poderoso fator de desmobilização sindical. Embora os sindicatos tenham tentado representar os interesses dos desempregados, o fato de estarem enfraquecidos no relacionamento com as empresas 
acaba por torná-los completamente voltados para a defesa do interesse daqueles que ainda têm um emprego. Essa linha de raciocínio amplia a margem do debate sobre a "crise", confere importância às transformações particulares e relativiza afirmações sobre a existência de uma tendência inexorável do coletivismo para o individualismo por ser uma interpretação unilateral de um conjunto de processos culturais complexos variados (Ramalho e Santana, 2002).

A partir da compreensão desse processo de mudança, Jácome Rodrigues (2002) enfatiza que estaríamos assistindo a um novo momento nas relações trabalhistas e um novo crescimento da ação do sindicalismo brasileiro, mas que não representa a volta ao período conflitivo dos anos 1970-1980 nem o defensivismo dos anos 1990. Este processo tem se apresentado no interior das empresas e se instalado em outros lugares sociais, nos quais já existia a tradição sindical. Assim, o início desse ressurgimento é balizado por novas organizações e orientações sindicais, abrangendo temas pouco explorados pelos sindicatos. Isto demonstraria que os sindicatos vêm articulando suas atividades mobilizatórias tradicionais com a participação em outras instâncias, tais como o debate e a intervenção em projetos de políticas públicas e sociais (Ramalho e SANTANA, 2003; Ferraz, 2014) e inserção no mercado financeiro por meio dos fundos de pensão (Grün, 2004; Jardim, 2009; Jardim e Jard da Silva, 2014).

Nesta perspectiva, o sindicalismo brasileiro vem buscando novas alternativas e estratégias de ação (Santana, 2000), visando enquadrar-se nas recentes configurações do capitalismo, como a inserção em novos espaços sociais: câmaras setoriais/ regionais, conselhos públicos, orçamento participativo etc. (Leite, 2003).

A partir da década de 1990, as transformações ocorridas no cenário político e econômico internacional, associadas às mudanças do processo produtivo, exerceram um impacto negativo principalmente para a economia das regiões mais industrializadas do país. Além disso, o processo de descentralização política acentuou ainda mais os problemas de organização dos estados e municípios brasileiros (Arretche, 1996). Neste contexto, vislumbrou-se uma tendência à formação de novos arranjos institucionais de integração horizontal.

Segundo Castel (2005), a homogeneidade do mundo do trabalho foi colocada em questão pelo desemprego em massa e pela precarização das relações de trabalho, tocando diretamente a baixa hierarquia. A solidariedade dos estatutos profissionais tende a transformar-se em concorrência entre iguais, ou seja, em vez de unir todos os membros de uma mesma categoria em torno de benefícios coletivos para a categoria, cada um busca melhorar ou manter sua própria condição.

Para Leite (2003) e Ramalho e Santana (2003), as novas estratégias sindicais como inserção do sindicato em espaços como câmaras setoriais/regionais e o apoio a movimentos sociais seriam respostas à crise econômica do setor. Da mesma forma, Rodrigues (2002) destaca as dificuldades dos sindicatos para mobilizar trabalhadores ante as mudanças no poder de barganha:

[...] a dificuldade para a mobilização dos trabalhadores e, portanto, para os sindicatos conservarem seu papel tradicional de representação de inte- 
resses amplo, embora possam ter sido negativas para o sindicato ou para o poder sindical estabelecimento muito mais flexível de normas de trabalho e de demarcação de tarefas para os empregados; maior envolvimento da força de trabalho nas decisões de produção e consequentemente redução da autoridade da administração com relação ao empregado; sistemas de recompensas destacados das tarefas e mais ligados às características individuais do empregado [...]. (Rodrigues, 2002, p. 179)

A partir da citação acima, compreende-se que as “modernas" formas de organização que estão ocorrendo no interior dos sindicatos caminham rumo a novas estratégias. Assim, ainda existem questões complexas para o sindicalismo se preocupar. É necessário atenção e inovação em suas ações para manter e ampliar sua importância histórica. ${ }^{2}$

Santana (2000) enfatiza que, diante da queda do poder de mobilização e da ausência no cenário nacional, os sindicatos procuraram ampliar sua pauta e inserir-se em novos espaços que lhes permitissem continuar existindo e se movimentando. $\mathrm{O}$ autor apresenta algumas estratégias utilizadas pelo movimento sindical: articulação com outros movimentos sociais - terra, moradia, justiça; abertura para novos temas - gênero, raça, educação; incorporação de práticas alternativas de intervenção, negociação e organização - câmaras setoriais/regionais, políticas públicas e sociais.

Por fim, Jácome Rodrigues (2002) ressalta que as respostas do sindicalismo não são apenas reações automáticas às mutações ambientais decorrentes das transformações que acontecem nos sindicatos enquanto organizações, mas também passam pelos interesses e valores das lideranças sindicais.

Nesta mesma linha de argumentação, procurando conciliar as análises que apontam para as transformações do capitalismo contemporâneo, assim como a alteração nos interesses e valores das lideranças sindicais, buscaremos, nas próximas seções deste artigo, abordar a presença das entidades sindicais no mercado financeiro, especialmente na gestão dos fundos de pensão. ${ }^{3}$

\section{O NOVO CONTEXTO DAS FINANÇAS}

A financeirização está inserida em um novo tipo simbólico de dominação social, a dominação financeira que se encontra no contraponto entre economia real e economia financeira. Este desencontro ressalta o poder da finança e a submissão da produção às finanças. Em outras palavras, o mercado não é uma forma neutra,

\footnotetext{
${ }^{2}$ Grozelier (2006) sugere que as entidades sindicais precisam de um projeto para que não fiquem simplesmente na resposta das estratégias dos patrões e do governo, ou seja, o movimento sindical precisa ter um plano para o futuro, com ideias e diretrizes.

${ }^{3}$ Jardim (2009) defende que a chegada de determinados sindicalistas na criação, gestão e fundos de pensão, assim como em outros espaços no mercado financeiro, passa a ser vista como uma nova estratégia de luta no seio do sindicalismo brasileiro.
} 
a liquidez financeira expressa a autonomia e a dominação das finanças sobre a sociedade. Assim, as finanças possuem um poder autônomo visto que desde suas origens carregam uma transgressão social devido à sua característica virtual, que a faz desconectada da atividade produtiva (ORLÉAN, 1999).

A dominação simbólica discutida acima pode ser exemplificada pelos próprios fundos de pensão, um ator cada vez mais dominante no espaço das trocas financeiras mundiais. Isto enfatiza que a financeirização trouxe uma considerável mudança nas relações das forças sociais, em proveito do capital financeiro, de seus atores, de seus porta-vozes e de suas instituições. Por conseguinte, as transformações propiciadas pelas finanças não traduzem apenas uma redistribuição de recursos financeiros e de rendas entre os diversos atores econômicos, mas possibilita ainda uma modificação profunda nas relações e nas regras sociais que regem essas relações, apontando uma evidente natureza social das finanças.

Para Zilbovicius e Dias (2009), no ambiente empresarial o discurso da flexibilidade é intrínseco ao mundo financeiro. Na mesma linha de argumentação, Orléan (1999) ressalta que é preciso gerar liquidez e possibilitar a mudança rápida de um investimento ao outro se eventualmente isso significar maiores ganhos. Dessa forma, nos espaços em que financeirização atua encontram-se empresas flexíveis, as quais não atendem a este modelo somente pelas demandas da competitividade em um mercado maduro e instável, mas também pela exigência de novos atores que a controlam, os investidores financeiros, e cuja lógica valoriza o custo de oportunidade, a liquidez, a flexibilidade do investimento.

Dessa forma, a flexibilidade é considerada uma propriedade dos sistemas de produção modernos, que competem: por variedade, por velocidade, por inovação. Para ser flexível em um sentido dinâmico, a organização deve ser capaz de aprender para conseguir gerir os eventos e estar fundamentada sobre um aprofundamento da profissão e possibilitar ciclos curtos de tomada de decisão (Zarifian, 1990).

Para Zilbovicius e Dias (2009), o contexto discutido acima se insere na globalização financeira acelerada, processo pelo qual os dirigentes financeiros dão ênfase ao crescimento dos números de negócios, em detrimento da rentabilidade dos investimentos. Ocorre a implantação da cultura do valor acionista em todos os níveis de organização. O valor agregado dos produtos passa a ser influenciado pelo mercado financeiro assim como as decisões das empresas, o que demonstra as transformações no setor produtivo, a qual insere-se à submissão das finanças.

O processo da financeirização altera os principais conceitos das organizações, ou seja, a competitividade que passa a ocorrer a partir de novos produtos e novas empresas, a eficiência que aumenta o valor líquido das ações e por último a produtividade a qual está inscrita na organização da velocidade do trabalho versus criatividade do trabalhador.

Ademais, o ambiente empresarial inserido na financeirização gera a produção de um conjunto de discursos inseridos no capitalismo dos acionistas: educação financeira; responsabilidade social e empresarial; sustentabilidade socioambiental; governança corporativa e transparência. Para Jardim (2011), inspiradas em programas de educação financeira, as finanças buscam criar racionalidade totalmente 
econômica e individualizante junto à sociedade. Os programas de educação financeira buscam a mudança de hábitos na relação sociedade versus finanças ou mudança de convenções cognitivas. O trecho abaixo ilustra essa alteração:

Em parte da dominação simbólica colocada pelos fundos de pensão, é possível observar que as firmas multinacionais - em alguns casos controladas parcialmente pelos fundos de pensão - tornam-se cada vez mais um ator dominante no espaço das trocas mundiais, o que mostra que a financeirização trouxe uma considerável mudança nas relações de força social, em proveito do capital financeiro, de seus atores, de seus porta-vozes e de suas instituições. (Jardim, 2011, p. 2)

Desse modo, a financeirização tem como meta criar valor para o acionista shareholder value, demonstrando que a empresa é vista como um portfólio de investimentos. Isto enfatiza que adicionar valor via produção é apenas um dos modos de valorização. As empresas passam a se submeter à pressão de melhorar suas performances financeiras e se alinhar às regras em vigor do mercado, levando à financeirização da produção. Contudo, também deve ser considerada a existência de um ambiente em que predominem as boas práticas financeiras e da produção, fazendo com que ambas se ajustem à nova lógica do capital. ${ }^{4}$

A citação seguinte demonstra a importância do trabalhador enquanto um acionista dentro deste contexto de financeirização:

[...] se uma firma quer criar valor, deve "transformar cada empregado em um criador de valor. [...] as decisões estratégicas devem ser descentralizadas para o nível operacional tanto quanto possível". Os trabalhadores seriam avaliados por métricas ligadas à criação de valor para o acionista: [...] os "direcionadores de valor" (value drivers), ferramentas cuja função seria traduzir as métricas econômicas para as diferentes atividades via indicadores, bem como guiar as decisões e ações [...] mostrando aos trabalhadores "como suas decisões e ações diárias podem influenciar o valor para o acionista". [...] uma mudança na relação capital-trabalho: a abertura do capital das empresas [...] [cria] a figura do "assalariado acionista". (Plihon, 2004, s/p)

No que se refere às relações de trabalho, a principal tese defendida é que a financeirização tende a privilegiar as formas de organização fundadas na autonomia. Isto representa um contraponto à organização clássica (taylorista/fordista) dominante durante o século XX. Zilbovicius e Dias (2009) chamam este modelo de disposição do trabalho de Novas Formas de Organização do Trabalho (NFOT),

\footnotetext{
${ }^{4}$ Por “financeirização da produção, entende-se um processo no qual a valorização do capital via sistema financeiro é preferida em detrimento da valorização do capital via produção, a lógica da produção sendo subordinada à lógica financeira" (Zilbovicius e Dias, 2009, p. 125).
} 
as quais representam uma oposição ao modelo taylorista/fordista, sobretudo no que se refere aos impactos na relação entre trabalho e o trabalhador.

Em suma, os autores Zilbovicius e Dias (2009), ao citar Gorz, afirmam que no mundo das finanças o valor dos ativos é fruto de julgamentos que são realizados sobre expectativas de geração de retornos futuros sobre investimentos presentes ou passados, não possuindo, necessariamente, relação com o mundo produtivo "real" e presente; o capital financeiro pode se tornar autônomo com relação à esfera da produção. Assim, o mundo produtivo representa o real - concreto - e o mundo financeiro o virtual - abstrato.

Para Chesnais (1995), o processo de mudança descrito neste contexto demonstra que houve uma mudança em relação às possibilidades de valorização do capital, privilegiando os mercados financeiros, nos quais o capital se valoriza sem passar pela esfera produtiva, relacionada à produção de bens e/ou serviços.

Em síntese, no contexto de financeirização da produção o trabalho é mais do que uma mercadoria, o qual se apresenta tão fluido quanto o capital financeiro, com a finalidade de garantir a liquidez desejada. A sociedade inserida na financeirização apresenta como principais características flexibilidade, autonomia e aceitação do elemento risco como inerente à vida moderna (Zilbovicius e Dias, 2009).

É nesse contexto de predomínio das finanças que o movimento sindical vai reencontrar seu lugar social, o que será o tema da próxima seção.

\section{SINDICALISTAS E MERCADO FINANCEIRO}

Conforme destacam Zilbovicius e Dias (2009) e Donadone e Jardim (2011), no processo de financeirização do século XXI as empresas contemporâneas estão submetidas ao jogo das finanças dos investidores institucionais. Nesse contexto, a concepção de gestão empresarial está voltada para satisfazer os interesses dos acionistas do mercado, diferentemente da empresa do século XX, quando a concepção de controle tinha como foco o consumidor e o produtor.

Os autores ressaltam ainda que a produção estaria em diálogo assimétrico com as finanças, o que traria consequências para o chão de fábrica, para os direitos sociais dos trabalhadores, para as condições de trabalho e para o sindicalismo. De forma provocadora sentenciam: "a luta de classe mudou de lugar; agora acontece no mercado financeiro" (Donadone e Jardim, 2011, p. 25).

Nesse contexto de dominação das finanças, existe uma possibilidade de as empresas realizarem deslocamento e/ou segmentação de suas atividades para nichos produtivos que diminuam o custo da produção e da mão de obra devido à ausência de leis e fiscalização; o uso de novas formas de gestão que enfatizam a participação individual dos trabalhadores e desestimulam a sindicalização; e o intenso processo de terceirização dentro nas empresas privadas e nas repartições públicas.

No Brasil, com a ascensão do governo de Luiz Inácio Lula da Silva (2003-2010), o sindicalismo intensificou as estratégias de ação orientadas para a participação no mercado financeiro por intermédio dos fundos de pensão e dos fundos 
de investimentos. Nesse contexto, Jardim (2009) destaca as seguintes ações sindicais: criação e gestão de fundos de pensão; presença ativa nos espaços do mercado financeiro; e defesa do investimento dos recursos dos fundos de pensão em atividades socialmente responsáveis e éticas.

A mesma autora afirma que segmentos do movimento sindical brasileiro têm reencontrado seu lugar socioeconômico, com uma agenda que inclui o diálogo com o mercado financeiro e a busca de novos interlocutores como os empresários, agentes do governo e agentes do mercado financeiro. Para alguns estudiosos, esta nova situação representa uma alteração nas estratégias de luta sindical que estariam em diálogo com o capital e não com o trabalhador.

Contudo, pesquisas desenvolvidas por Grün (2004), Jardim (2009), Sória e Silva (2011) indicam que os sindicatos dos setores bancário, eletricitário, telefônico, petroleiro, bem como dirigentes das três grandes centrais sindicais do país, CUT, CGT e FS, passaram a reivindicar a criação de previdência privada para seus associados e participação ativa nos conselhos dos fundos de pensão. Dessa forma, estendem o mandado de representação dos empregados na empresa para os fundos de pensão, se colocando como legítimos representantes e defensores da poupança dos trabalhadores (Grün, 2003, 2004).

Dentre os gestionários de fundos de pensão, Jardim (2009) sublinha a presença dos sindicalistas, que se tornaram grandes interessados pela criação e, sobretudo, pela gestão destes fundos, visando fazer parte dos processos decisórios do capitalismo. Trata-se de um projeto em âmbito internacional, que se evidenciou no Brasil, especialmente, durante o governo de Luiz Inácio Lula da Silva. ${ }^{5}$ Portanto, o sindicalismo tem sido confrontado com a promessa de novas expectativas, as quais pressupõem o ganho de certo poder e controle sobre o capitalismo.

Como consequência, os sindicalistas se veem confrontados com diferentes tipos de atores, tais como governos, grupos financeiros, empresas de consultorias e os "tradicionais dirigentes" de fundos de pensão, fundos de investimentos detentores da expertise necessária ao mercado financeiro. Nessa locução e interlocução, observa-se a existência de tensões e alianças, de divergências e mesmo de convergência dos atores envolvidos na temática indicada - empresários, sindicalistas, trabalhadores, membros dos governos, financistas.

No Brasil, foi possível observar que as centrais passaram a unificar os sindicatos em torno da vultosa soma dos fundos de pensão, tendo discursivamente a preocupação com a financeirização do capital, a desigualdade social, os investimentos éticos, a responsabilidade social e o capitalismo dos acionistas (Jardim, 2009; Sória e Silva, 2015). O governo Lula criou um ambiente de negócios particularmente favorável ao desenvolvimento do sindicalismo de finanças. ${ }^{6}$

\footnotetext{
${ }^{5}$ Jardim (2009) observa que a gestão sindical dos fundos de pensão acontece também nos Estados Unidos, França, Canadá e Reino Unido, dentre outros países.

${ }^{6} \mathrm{O}$ ex-presidente realizou uma histórica visita à Bolsa de Valores de São Paulo (Bovespa), em 5 de agosto de 2002, quando defendeu a popularização do mercado de capitais. A ocasião foi denominada pela
} 
O quadro que estamos descrevendo de aproximação entre sindicalistas e mercado financeiro apresenta uma nova variável na história do sindicalismo brasileiro, e uma nova natureza na relação capital-trabalho. Antunes (2011) (re)define esse sindicalismo como sindicalismo de negócio. Jardim (2009) considera uma forma de domesticação do capitalismo, no sentido de uso das finanças para propósitos sociais. Portanto, é na polissemia de diversas vozes e discursos, na qual dialogam distintos atores sociais, que a entrada de sindicalistas em novos espaços sociais como os fundos de pensão - acontece. Os discursos sociais e preocupações financeiras se encontram nas mesas de reunião. ${ }^{7}$

Podemos afirmar que a presença de sindicalistas no mercado financeiro nos anos 2000 forma um espaço social em que os diversos agentes envolvidos colaboram para sua difusão e consolidação nas organizações sindicais. Para isso, se utilizam da possibilidade de um mínimo de entendimento comum sobre o tema da participação - conhecimentos prévios adquiridos - como uma forma de alcançar os seus objetivos específicos em relação ao futuro desejado nas relações trabalhistas.

Ainda com inspiração em Pierre Bourdieu (1989), podemos afirmar que a disputa por fundos de pensão leva a uma luta - simbólica - entre defensores e críticos da estratégia sindical. No movimento sindical brasileiro, especialmente, não existe consenso. Enquanto Jardim (2011) afirma que o cenário está circunscrito por uma "elite sindical" constituída por sindicalistas da CUT que defendem o tema e outros da mesma base que ignoram o debate, bem como os sindicalistas do PSTU se colocam contra o assunto. Da mesma forma, segmentos da Força Sindical e da CGT também são defensores dessa agenda que movimenta bilhões de reais. Finalmente, é importante informar que os sindicalistas da CUT disputam a gestão sindical com profissionais do mercado financeiro.

Em suma, tanto empresários como sindicalistas dividem as mesmas preocupações: pagar as aposentadorias dos cotistas; aumentar a rentabilidade dos fundos; criar carteiras de investimentos; adquirir títulos da dívida pública; defender fundos éticos e de responsabilidade social com princípios de governança corporativa com os recursos dos fundos de pensão.

As polêmicas estratégias expostas acima nos permitem falar provisoriamente em um novo éthos sindical, o que abordaremos mais detalhadamente na próxima seção deste trabalho.

\footnotetext{
imprensa como a "Queda do Muro de Berlim". Além de diversos elementos simbólicos, o governo institucionalizou as Leis $n^{\circ} 108 / 2001$ e nº109/2011 que autorizam a criação e a gestão de fundos de pensão sindicais.

${ }^{7}$ A partir do conceito de Bourdieu (1989), entende-se por polissemia um sentido compartilhado para um determinado conceito, onde os entendimentos implícitos na sociedade em torno de sua definição fixam-se neste compartilhamento apenas parcial, que garante um mínimo de acordo e evita uma crise na relação entre os contendores, para depois evoluir como conflitos simbólicos, em que cada parte tenta registrar como correta a sua versão específica do entendimento.
} 


\section{ETHOS SINDICAL E MERCADO FINANCEIRO}

Boltanski e Chiapello (1999) indicam que o capitalismo cria justificativas ideologias - para sustentar o engajamento dos protagonistas do capital que passam a compartilhar um conjunto de crenças associadas à ordem capitalista. As novas ideologias formam o espírito do capitalismo de cada época, a produção de sentido do período histórico, ou um éthos, no sentido aqui empregado.

Para engajar os interessados, o capitalismo deve incorporar um espírito capaz de oferecer perspectivas sedutoras e estimulantes de vida, oferecendo, ao mesmo tempo, garantias de segurança e razões morais para se fazer o que é feito. São essas crenças que dão respaldo ao cumprimento de tarefas mais ou menos penosas e a adesão a um estilo de vida favorável a ordem capitalista (Boltanski e Chiapello, 1999).

Desse modo, estamos diante de uma nova fase do capitalismo, caracterizando um alto grau de conexão e uma alta densidade de fluxos de comunicação. Esse o conexionismo, o qual é regido por estratégias individuais que se deslocam em uma rede fluida sem as fronteiras burocráticas das organizações. Ou seja, estabelece-se uma capacidade de converter capital social em capital econômico através das ligações entre pontos dispersos de um sistema altamente integrado (Pauli, 2009).

Ainda segundo Boltanski e Chiapello (1999), o capitalismo possui modelos de justificação social e ordens de justiça equilibrando a tensão permanente entre sua autodestruição com as exigências morais de bem comum. Assim, as ordens de justiça a partir do mundo conexionista elaboram um conceito moral, superando, o imperativo ético característico do capitalismo industrial - inscrito no ascetismo moral da ética calvinista apontada por Max Weber (2004) - bem como do capitalismo monopolista de Estado - representado pelo welfare state.

Dessa forma, o terceiro espírito se expressa pela tentativa da superação do hiato entre o projeto capitalista e sua realização através de uma refundação da sua moralidade estabelecendo uma nova ordem de justiça (Pauli, 2009).

Com inspiração em Bolstanki e Chiapello (1999), argumentamos que o conjunto de crenças compartilhadas pelos atores sensibilizados e cooperadores deste projeto de criação e gestão de fundos de pensão e fundos de investimentos é compartilhado em um âmbito maior que o das leis, ou seja, por meio de instituições, ideias e crenças, mais concretamente, pela cultura, pelo éthos da época. ${ }^{8}$

Sauviat (2003) contribui para o debate afirmando que as diferentes iniciativas sindicais em direção aos fundos de pensão emergiram principalmente nos países em que havia declínio relativo na capacidade de intervenção dos sindicatos, ou seja, declínio de greve, das taxas de sindicalização e de negociação coletiva. Aglietta (2005), por sua vez, ao analisar o caso francês, defende como positiva a gestão dos fundos de pensão por sindicatos e trabalhadores, já que as entidades sindicais

\footnotetext{
${ }^{8}$ Para Oliveira (2014), a articulação entre uma nova formação cultural e um grupo ou fração de classe social com um novo éthos (como gestores, consultores ou empresários) está no centro da difusão de uma nova forma de comportamento social e econômico inseridos no capitalismo contemporâneo.
} 
devem contribuir à socialização do capitalismo através do salário. Sobre a mesma questão, Lordon (2000, p. 96) ressalva que: "Mesmo que o acionista salarial seja visto atualmente como símbolo da reconciliação entre capital e trabalho há, na verdade, um gabinete especializado que decide as prioridades de investimento".

No Brasil, a criação desse éthos foi um longo processo histórico. O mercado de fundos de pensão foi regulamentado a partir do final dos anos 1970, mas até o início dos anos 2000 não eram temas priorizados pelos sindicatos (Jardim e Jard da Silva, 2014). Isto ocorria porque a previdência complementar não era considerada um assunto de relevância pelas entidades sindicais, sendo considerada uma espécie de concessão dirigida aos funcionários de empresas estatais, além do fato da previdência pública ainda cobrir grande contingente de trabalhadores (Gushiken e Gonçalves, 2002). ${ }^{9}$

No final dos anos 1990, aumentaram as discussões em torno dos fundos de pensão. Neste mesmo período, os sindicatos passam a ver estes recursos como direito do trabalhador, despertando a consciência dos dirigentes sindicais sobre a poupança previdenciária. Consequentemente, essas discussões começam a entrar na agenda do sindicalismo brasileiro. O discurso sindical, para se inserir nesta nova agenda, valeu-se dos princípios da transparência e da participação democrática nos conselhos - composto por sindicalistas, trabalhadores, consultores financeiros e funcionários dos fundos (Gushiken e Gonçalves, 2002).

Neste contexto, a agenda sindical passou a incluir a demanda por novos planos previdenciários e exigir maior transparência e participação na gestão dos planos existentes, realizando uma conciliação entre os interesses dos participantes com as necessidades de financiamento da atividade produtiva, ou seja, cumprir a meta de investimentos, mas sem desrespeitar os desejos dos integrantes (Reis, 2002).

O disciplinamento dos mercados financeiros, sua regulação e controle são tarefas fundamentais devido à vulnerabilidade a que o mercado financeiro está exposto. Assim, os sindicalistas e atores sociais sensibilizados pela temática defendem que os fundos de pensão devem assumir importância estratégica na luta contra os processos de financeirização da economia mundial, já que os recursos previdenciários contribuem fortemente para a alavancagem do referido processo (Gushiken e Gonçalves, 2002).

Segundo Jardim (2009), a veemente defesa da inserção sindical nas finanças via fundos de pensão apresentada por Gushiken e Gonçalves (2002) pode ser interpretada como uma mudança de éthos. Isto é, os sindicalistas historicamente resistentes ao mercado passam a demonstrar relativo conforto ao discorrer sobre finanças e fundos de pensão como alternativa à proteção social, acreditando realmente nos fundos como provedores de solidariedade, laços sociais e, ainda, como nova bandeira de ação. Ou seja, não se trata de uma mudança institucional somente, em termos de legislação, mas cultural, cognitiva, ou seja, na forma de pensamento dos sindicalistas.

\footnotetext{
${ }^{9}$ Luiz Gushiken foi um dos atores sindicais pioneiros na defesa da inserção de sindicalistas no mercado financeiro via conselhos de fundos de pensão e dos conselhos de investimentos no caso dos RPPS.
} 
Os resultados das pesquisas realizadas por Jardim (2009) e Oliveira (2014) demonstram que os sindicalistas, sobretudo os da CUT, se relacionam com os fundos de pensão e fundo de investimentos dos Regime Próprio de Previdência Social (RPPSs) sem constrangimentos, já que possuem a crença de que trabalham em prol dos trabalhadores, negando a assertiva de que estariam se vendendo ao capital. Trata-se, sobretudo, de uma mudança cultural dos sindicalistas que passam a defender uma nova estratégia de ação no capitalismo de finanças.

Os dirigentes sindicais argumentam que o envolvimento dos sindicatos com o mercado financeiro é uma forma de lutar contra a especulação e a financeirização do capitalismo. Assim, utilizar o próprio capitalismo na luta contra a financeirização e a especulação da economia seria o novo éthos sindical. Utilizar os fundos de pensão como inclusão social é o éthos de moralização do capitalismo bem como legitimá-los como esquema de aposentadoria é a nova solidariedade de classe (Jardim, 2009).

Nesta inovadora perspectiva sindical, construir a proteção social a partir das finanças é a saída para a crise de segurança que vive toda a sociedade brasileira. Além disso, melhor que os fundos sejam geridos por sindicalistas do que por profissionais do mercado, sem vínculo social e político com os trabalhadores, em última instância, os donos dos recursos dos fundos de pensão.

\section{CONSIDERAÇÕES FINAIS}

Desde meados dos anos 1990 alguns segmentos sindicais passaram a se interessar pela criação e gestão de previdência privada, sobretudo dos fundos de pensão, inserindo novos temas na agenda sindical.

O fenômeno chama a atenção por se tratar de uma diretriz de caráter inédito, a qual coloca parte dos sindicalistas diante de novos desafios, de novos interlocutores e na interação com o mercado financeiro. Portanto, extrapolando o tripé clássico da ação sindical - salário, condições de trabalho e redução da jornada de trabalho -, o movimento sindical busca unificar os sindicatos em torno da administração responsável de vultosas somas financeiras, tendo a preocupação com a "moralização" do capital, a desigualdade social e com investimentos éticos e de responsabilidade social.

Nessa perspectiva, os sindicalistas deixaram de responder simplesmente "não" às propostas do mercado, e passaram a considerar a possibilidade de unir interesses que, até então, pareciam antagônicos. Dessa maneira, começam a associar o papel de sindicalistas à responsabilidade financeira, além da já conhecida responsabilidade de representação trabalhista.

Os fundos de pensão apareceram como uma alternativa à "crise das estratégias e finalidades tradicionais”. Assim, buscando se adaptar a esse novo cenário, o movimento sindical construiu justificativas que são permeadas de valores morais, sociais e políticos para sua inserção no mercado, ao mesmo tempo que (re)significou seu discurso. 
Por fim, cabe lembrar que para a legitimidade dos fundos de pensão e dos fundos de investimentos municipais os dirigentes sindicais envolvidos com a temática pontuam a incapacidade da previdência social, da mesma forma que passam a afirmar os fundos via capitalização como nova forma de solidariedade. ${ }^{10} \mathrm{Em}$ síntese, o mercado de fundos de pensão que está se constituindo é resultado de interações, conflitos e consensos entre diferentes atores, com diferentes motivações, num diálogo constante entre sindicalistas, governos e mercado financeiro.

\section{REFERÊNCIAS BIBLIOGRÁFICAS}

AGLIETTA, M. (2005) Associer les salariés à la gestion des entreprises. Paris: Liberation.

ANTUNES, R. (1995) Adeus ao trabalho? Ensaio sobre as metamorfoses e a centralidade do mundo do trabalho. Campinas: Unicamp.

ANTUNES, R. (2011) Sindicalismo de classe versus sindicalismo negociador de Estado. Disponível em : < https://goo.gl/xzQoXE>, Acesso em 10 Dez. 2018.

ARRETCHE, M. (1996) "Mitos da descentralização: mais democracia e eficiência nas políticas públicas? Revista Brasileira de Ciências Sociais, 11 (31): 1-27.

ALMEIDA, M. H. T. (1996) Crise Econômica e Interesses Organizados: o Sindicalismo no Brasil dos Anos 80. São Paulo: EDUSP.

BEYNON, H. (2003) Limites do sindicalismo. Londrina: Práxis.

BOITO Jr. A. (1991) O sindicalismo de Estado no Brasil. São Paulo: Hucitec.

BOLTANSKI, L.; CHIAPELLO, E. (1999). O novo espírito do capitalismo. São Paulo: Martins Fontes. BOURDIEU, P. (1989) O poder simbólico. Lisboa: Difel.

CASTEL, R. (2005) A Insegurança Social: o que é ser protegido? Petrópolis: Vozes.

CHESNAIS, François. (1995) A Finança Mundializada. São Paulo: Boitempo.

DONADONE, J; JARDIM, M.A.C. (2011). Centralidades e as Fronteiras da Empresa do Século XXI. Bauru: EDUSC.

FERRAZ, A. S. (2014) “Novos rumos do sindicalismo no Brasil”, Revista Brasileira de Ciências Sociais, 29 (86): 109-123.

GROZELIER, A. M. (2006) "Les syndicats difficilement em phase avec les transformations du travail”. Revista Mouvements, Paris, (43): 15-22.

GRÜN, R. (2003) "Fundos de pensão no Brasil do final do século XX: guerra cultural, modelos de capitalismo e os destinos das classes médias”, Revista Mana, 9 (2): 7:38.

GRÜN, R. (2004) "A evolução recente do espaço financeiro no Brasil e alguns reflexos sobre a arena política”. Revista de Ciências Sociais, 47 (1): 5-47.

GUSHIKEN, L. \& GONÇALVES, R. (2002) “Os fundamentos de um código de ética para investimentos e as novas perspectivas sindicais em fundos de pensão”. In Gushiken e Associados, orgs. Previdência complementar e regime próprio. Indaiatuba: Instituto Integrar.

JÁCOME RODRIGUES, I. (1991) Comissão de Fábrica e Trabalhadores na Indústria. São Paulo: Cortez/FASE.

JÁCOME RODRIGUES, I. (2002) "Um laboratório das relações de trabalho: o ABC paulista nos anos 90”, Tempo Social., 14 (1): 137-157.

JARD DA SILVA, S. (2001) "Companheiros servidores: o avanço do sindicalismo do setor público na CUT”. Revista Brasileira de Ciências Sociais, 16 (46): 130-146.

JARDIM, M. A. C. (2009) Entre a solidariedade e o risco: sindicatos e fundos de pensão em tempos de Governo Lula. São Paulo: Annablume.

\footnotetext{
${ }^{10}$ Sobre a atuação dos sindicalistas nos fundos de previdência municipais, especialmente na região metropolitana do ABC Paulista, ver o trabalho de Oliveira (2014).
} 
JARDIM, M. A. C.. (2011) “Natureza social das finanças”. Revista Espaço de Diálogo e Desconexão, 4 (1): 1-17. Disponível em: <http://seer.fclar.unesp.br/redd/article/view/5052/4190/>. Acesso em: 15 jul. 2015.

JARDIM, M. A. C.; JARD DA SILVA, S. (2014) “A criação dos fundos de pensão para servidores públicos federais no Brasil”. $38^{\circ}$ Encontro Anual da Anpocs, Caxambu. Disponível em: <<http://www. anpocs.org/portal/index.php?option=com_docman\&task=doc_view\&gid=9120\&Itemid=456>. Acesso em: 02 Ago. 2018.

JARDIM, M. A. C.; JARD DA SILVA, S. (2015) "New Pension Legislation for Federal Public Servants in Brazil", Global Journal of Human-Social Science, 15 ( 2): 20-29.

LEITE, M. P. (2003) Trabalho e sociedade em transformação: mudanças produtivas e atores sociais. São Paulo: Abramo.

LORDON , F. (2000) Fonds de pension piége a cons? Mirage de la démocratie actionnariale. Paris, Raison d'agir.

NORONHA, E. (1991) "A explosão das greves na década de 80"; In BOITO JR., A. O sindicalismo brasileiro nos anos 90, Rio de Janeiro: Paz e Terra.

OLIVEIRA, J. (2014) Uma análise da presença sindical nos institutos de previdência municipal do ABC. Dissertação de mestrado, Universidade Estadual Paulista, Araraquara.

ORLÉAN, A. (1999) Le Pouvoir de la Finance. Paris, Odile Jacob.

PAULI, J. (2009) "Estratégias individuais e ordens de justiça no capitalismo conexionista". In CONGRESSO BRASILEIRO DE SOCIOLOGIA, 14, Rio de Janeiro. Disponível em: < https://goo.gl/ GZ9Tsc>, Acesso em: 12 Dez. 2018.

PLIHON, D. (2004) Le Nouveau Capitalisme, Paris, La Découverte.

RAMALHO, J. R.; SANTANA, M. A. (2002) "A indústria automobilística no Rio de Janeiro: relações de trabalho em um contexto de desenvolvimento regional”, In: NABUCO, R. M. et al. (orgs.). Indústria automotiva: a nova geografia do setor produtivo. Rio de Janeiro: DP\&A.

RAMALHO, J. R.; SANTANA, M. A.. (2003) “Trabalhadores, sindicatos e a nova questão social”, In: (Orgs.) M. A. Santana \& J. R. Ramalho, Além da fábrica: Trabalhadores, sindicatos e a nova questão social. São Paulo: Boitempo.

REIS, A. (2002) Fundos de pensão em debate. Distrito Federal, Editora Brasília Jurídica.

RODRIGUES, L. (1999 [2002]) Destino do Sindicalismo. São Paulo: EdUSP.

SALERNO, M. S. (2004) "Da rotinização à flexibilização: ensaio sobre o pensamento crítico brasileiro de organização do trabalho", Gestão da Produção, 11 (1): 21-32.

SANTANA, M. A. (2000) "As centrais sindicais brasileiras e a reestruturação produtiva: análises e propostas”, Sociologias, 4: 186-225, Porto Alegre: PPGS/UFRGS.

SAUVIAT, C. (2003) Syndicats et marchés financiers. Paris: Ires.

SÓRIA E SILVA, S. (2011). Insersecção de classes: fundos de pensão e sindicalismo no Brasil. O sindicato brasileiro em Sociologia. Tese de doutorado, Universidade Estadual de Campinas, Campinas.

SÓRIA E SILVA, S. ( 2015) "As relações entre sindicalismo e fundos de pensão no governo Lula". In OLIVEIRA, R. V. et al. (org). O sindicalismo na era Lula: paradoxos, perspectivas e olhares. Belo Horizonte: Fino Traço.

ZARIFIAN, P. (1990) La Nouvelle Productivité, Paris, L'Harmattan.

ZILBOVICIUS, M; DIAS, V. (2009) "Trabalho e criação de valor: financeirização da produção e novas formas de organização do trabalho”. In CARLETTO, A. P M. et al. (org) Sociologia econômica e das finanças: um projeto em construção. São Carlos: EDUFSCAR.

WEBER, M. (1905 [2004]) A ética protestante e o espírito do capitalismo. São Paulo: Companhia de Letras.

WEFFORT, Francisco C. (1972) "Participação e conflito industrial: Contagem e Osasco: 1968”. Cadernos Cebrap, n. 5, São Paulo: Cebrap. Disponível em < http://bibliotecavirtual.cebrap.org. $\mathrm{br} /$ ?r=acervos/busca\&titulo=contagem $>$. Acesso em: 04 Jan. 2019. 